\title{
Incorporation of Nanohybrid Films of Silica into Recycled Polystyrene Matrix
}

\author{
Genoveva Hernández-Padrón,, ${ }^{1}$ Domingo Rangel-Miranda, ${ }^{2}$ \\ Gerardo Cedillo, ${ }^{3}$ and Alejandra Blanco-Hernández ${ }^{4}$ \\ ${ }^{1}$ Departamento de Nanotecnología, Centro de Física Aplicada y Tecnología Avanzada, Universidad Nacional Autónoma de México, \\ Campus Juriquilla, 76230 Querétaro, QRO, Mexico \\ ${ }^{2}$ Departamento de Ingeniería Molecular de Materiales, Centro de Física Aplicada y Tecnología Avanzada, \\ Universidad Nacional Autónoma de México, Campus Juriquilla, 76230 Querétaro, QRO, Mexico \\ ${ }^{3}$ Instituto de Investigaciones en Materiales, Universidad Nacional Autónoma de México, Ciudad Universitaria, Circuito Exterior s/n, \\ 04510 México City, DF, Mexico \\ ${ }^{4}$ Facultad de Química, Universidad Autónoma de Querétaro, Cerro de las Campanas s/n, 76010 Santiago de Querétaro, QRO, Mexico
}

Correspondence should be addressed to Genoveva Hernández-Padrón; genoveva@unam.mx

Received 22 May 2015; Revised 1 July 2015; Accepted 28 July 2015

Academic Editor: Kangtaek Lee

Copyright (c) 2015 Genoveva Hernández-Padrón et al. This is an open access article distributed under the Creative Commons Attribution License, which permits unrestricted use, distribution, and reproduction in any medium, provided the original work is properly cited.

\begin{abstract}
An alternative for the reutilization of polystyrene waste containers consisting in creating a hybrid material made of $\mathrm{SiO}_{2}$ nanoparticles embedded in a matrix of recycled polystyrene (PSR) has been developed. Recycled polystyrene functionalized (PSRF) was used to influence the morphological and antifog properties by the sol-gel synthesis of nanohybrid silica. To this end, silica nanoparticles were produced from alkoxide precursors in the presence of recycled polystyrene. The functionalization of this polymeric matrix was with the purpose of uniting in situ carboxyl and silanol groups during the sol-gel process. In this way, opaque or transparent solid substrates can be obtained, with each of these endowed with optical conditions that depend on the amount of reactants employed to prepare each nanohybrid specimen. The nanohybrids were labelled as $\mathrm{SiO}_{2} / \mathrm{PSR}$ ( $\mathrm{HPSR}$ ) and $\mathrm{SiO} \mathrm{O}_{2} / \mathrm{PSRF}$ (HPSRF) and their properties were then compared to those of commercial polystyrene (PS). All the prepared samples were used for coating glass substrates. The hydrophobicity of the resultant coatings was determined through contact angle measurement. The nanohybrid materials were characterized by FT-IR and ${ }^{1} \mathrm{H}-\mathrm{NMR}$ techniques. Additionally, TGA and SEM were employed to determine their thermal and textural properties.
\end{abstract}

\section{Introduction}

In the recent decades, the development of new plastics has been a great challenge for the scientific and technological community, because of the harmful influence of plastics on the environment and the accumulation of polymeric materials. Additionally, the degradation time of these materials is very long and nonrenewable resources have been declining in tandem with the growth of plastics engineering [1]. This situation has forced society to diminish the use of plastic materials in the immediate future and so, now, these substances must be recycled [2].

Inorganic-organic hybrids [3, 4] are rapidly emerging as alternatives to traditional antifog, self-cleaning, and UV protected materials, since they combine the chemical and mechanical properties of both inorganic and organic components [5-7]. In another sense, human health protection and environmental remediation have been constantly deteriorated. In the following work we propose an application for reusing polystyrene, which is commonly used for transporting fast food disposables, food trays, and beverage containers and as a general packaging product.

Polymers can be reused as intelligent window coatings with water repellent properties, antifogging agents, UV protectors, or self-cleaning products. It is known that polymers such as HDPE, LDPE, PS, or PP are used for these applications; the PS surface can be modified with a hydrophobic group to improve these characteristics [8-10]. Also, nano- or 
microsilica particles incorporated into the polymer matrix combine the useful polystyrene features. The incorporation of these $\mathrm{SiO}_{2}$ particles can be performed via the sol-gel method [11]; this process allows a better control of the hydrophobic coating properties. The initial conditions can be manipulated to improve the mechanical, optical, thermal, antifog, and other properties of new materials $[12,13]$.

Coatings are used to indicate the deposition of a material on the surface of another one; the purpose is to provide on the covered area some characteristic that the material has not yet attained by itself [14]. Organic coatings are those applied in liquid state form on a surface after drying and usually result in a continuous solid covering layer. The drying processes involve chemical reactions or simple evaporation of the solvent, such as in paints, lacquers, enamels, and varnishes [11]. The effect of the coating is to provide some type of insulation, protection by adding a surface or interfacial property, while keeping the original properties of the covered material $[15,16]$.

Inorganic-organic hybrid composites are rapidly emerging as alternatives to traditional self-cleaning, antifog, or UV protection materials [17] since coatings alone usually exhibit no sufficient wear protection properties due to their low densities, thickness the wear and stress resistance of lining materials, but they can be improved with the incorporation of new hybrid composites.

There is particular interest in the functionalized polymers from the technological and scientific points of view; therefore, the inclusion of nanoparticles to improve the properties of polymers or resins [17] and even recycled polymers is a highly appreciated alternative.

In this work hybrid materials were prepared by incorporating silica nanoparticles $\left(\mathrm{SiO}_{2}\right)$ into recycled polystyrene matrices (PSR). Recycled polystyrene was functionalized (PSRF) by using abietic acid. The functionalization of the recycled polymeric matrix has the purpose of uniting carboxyl with silanol groups in situ during the sol-gel process. Infrared and ${ }^{1} \mathrm{H}$-NMR spectroscopies were used to verify the functionalization of polystyrene and incorporation into it of silica particles. The prepared nanohybrids were labeled as $\mathrm{SiO}_{2} / \mathrm{PSR}$ (HPSR) and $\mathrm{SiO}_{2} / \mathrm{PSRF}$ (HPSRF), respectively, and then were compared to commercial crystal polystyrene (PS) and their corresponding hybrids.

\section{Experimental Procedure}

2.1. Materials and Methods. The materials used in this work were (a) tetraethyl orthosilicate (TEOS) (Aldrich Chem.), (b) $\mathrm{CO}_{2}$-free triple distilled water, (c) toluene (reactive grade) (J. T. Baker), (d) polystyrene containers that were used as the recycled polymer, (e) commercial crystal polystyrene (Resirene Co.), (f) benzoyl peroxide (Sigma-Aldrich 99\%), and $(\mathrm{g})$ abietic acid (Sigma-Aldrich 70\%).

\subsection{Functionalization of Polystyrene (Commercial and Recy-} cled). The functionalization of commercial or recycled polystyrene was made from a solution of toluene subjected to mechanical stirring. In order to prepare the PSF or PSRF substrates, abietic acid (AA) and benzoyl peroxide employed as initiator (i) (i.e., an i/AA molar ratio of 0.376 ) were added to the PS or PSR materials and refluxed for $1 \mathrm{~h}$ under mechanical stirring. The method of synthesis and the preparation conditions for preparing the modified polystyrene (PSF) materials have been described elsewhere [18].

2.3. Hybrid Materials Preparation. The $\mathrm{PS}-\mathrm{SiO}_{2}, \mathrm{PSR}-\mathrm{SiO}_{2}$, $\mathrm{PSF}^{-S_{\mathrm{O}}}{ }_{2}$, and $\mathrm{PSRF}-\mathrm{SiO}_{2}$ hybrid materials were prepared from solutions of nonfunctionalized or functionalized recycled polystyrene (PSR or PSRF, resp.). Previously, the PS or PSF commercial solids were dissolved in toluene. TEOS was dissolved in another glass beaker containing a volume of toluene equal to the quantity employed to prepare the above PS or PSR solutions. Afterward, PS, PSF, PSR, or PSRF solutions were added sequentially to the beaker containing the TEOS/toluene mixture. The reactant mixture was kept under stirring and refluxing conditions for $2 \mathrm{~h}$. The TEOS molar ratios employed in the above preparations corresponded to 2.5 and $6.3 \times 10^{-5} \mathrm{~mol}$ of initiator and were added to the PS and PSR polymers.

2.4. Substrates Coating. Clean glass plates of $4 \times 1$ in. and $4.8 \times$ $10^{-2} \pm 0.00005$ in. thickness were coated with PS, PSF, PSR, PSRF, HPS, HPSF, HPSR, and HPSRF films, respectively. The surface of each glass plate was immersed (at a rate of $5 \mathrm{mms}^{-1}$ ) inside the polymers solutions under study.

2.5. Characterization Techniques. The characterization of the obtained hybrid materials was carried out by FT-IR spectroscopy. Infrared analysis (FT-IR) was performed on a Bruker Vector 33 spectrometer, by using the transmittance technique. The samples were prepared as thin films.

The ${ }^{1} \mathrm{H}-\mathrm{NMR}$ spectra were recorded on a Bruker Avance 400 spectrometer, with a BBI $400 \mathrm{MHz}$ SB $5 \mathrm{~mm}$ with $\mathrm{z}$ gradient probe and TOPSPIN 2.1 software; all samples were previously dissolved in $\mathrm{CDCl}_{3}$ at room temperature.

In turn, TGA/DTA analyses were carried out in a DuPont 951 instrument operated in an air atmosphere at a rate of $10 \mathrm{~K} \mathrm{~min}^{-1}$.

The contact angle was measured on the surface of the coated material that was prepared on the glass surface. One drop of water $(1 \mu \mathrm{L})$ was placed on the surface and then a photograph was taken of the solid-liquid interface with a camera Cannon Power Shot Sx30 IS. These images were transformed to gray scale and analyzed with the MatLab 6 program, version 6.0.0.88, and five measurements of each sample were made.

Scanning Electron Microscopy (SEM) observations were carried out in a Jeol JSM-5200 scanning microscope. The samples were coated with carbon by vacuum evaporation.

\section{Results and Discussion}

PS, PSF, HPS, and HPSF FT-IR spectra are shown in Figures 1 and 2, in the ranges of 3300 to $2600 \mathrm{~cm}^{-1}$ and 2000 to $400 \mathrm{~cm}^{-1}$, respectively. 




FIGURE 1: FT-IR spectra in the range of $3300-2600 \mathrm{~cm}^{-1}$ of (a) PS, (b) PS-F, (c) HPS, and (d) HPSF materials.

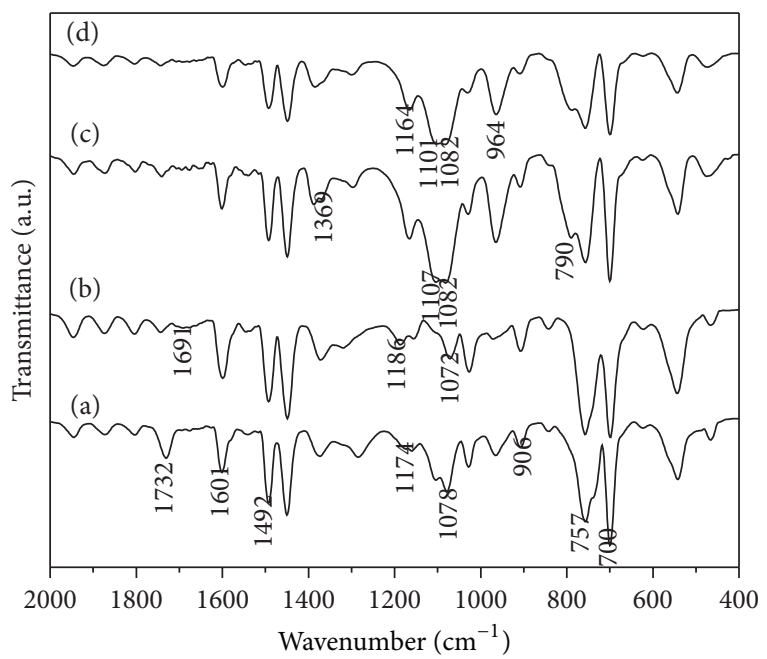

FIGURE 2: FT-IR spectra in the range of $2000-400 \mathrm{~cm}^{-1}$ for (a) PS, (b) PS-F, (c) HPS, and (d) HPSF substrates.

Polystyrene (PS) presents characteristic absorption bands at 3080,3060 , and $3027 \mathrm{~cm}^{-1}$ corresponding to aromatic $\mathrm{CH}$ groups; likewise signals from the aromatic hydrogen present in ${ }^{1} \mathrm{H}$-NMR spectra of polystyrene and recycled polystyrene (PSR) appear between 6 and 7.5 ppm (Figures 5(a) and 6(a)). Polystyrene presents bands at 2924 and $2852 \mathrm{~cm}^{-1}$ proceeding from $\mathrm{CH}_{2}$ asymmetric and symmetric vibration, respectively [19] (Figure 1(a)). On the other hand, the signals appearing at $2.4 \mathrm{ppm}$ in Figures 5(a) and 6(a) correspond to aliphatic hydrogen while that of the region between 1 and $2.3 \mathrm{ppm}$ corresponds to methine $(\mathrm{CH})$ and methylene groups $\left(\mathrm{CH}_{2}\right)$ [20].

Figure 2(a) shows aromatic ring absorption bands at 1601, 1492 , and $700 \mathrm{~cm}^{-1}[19]$.

The spectrum of the functionalized polystyrene (PSF) containing abietic acid (Figure 1(b)) shows a broadband in the

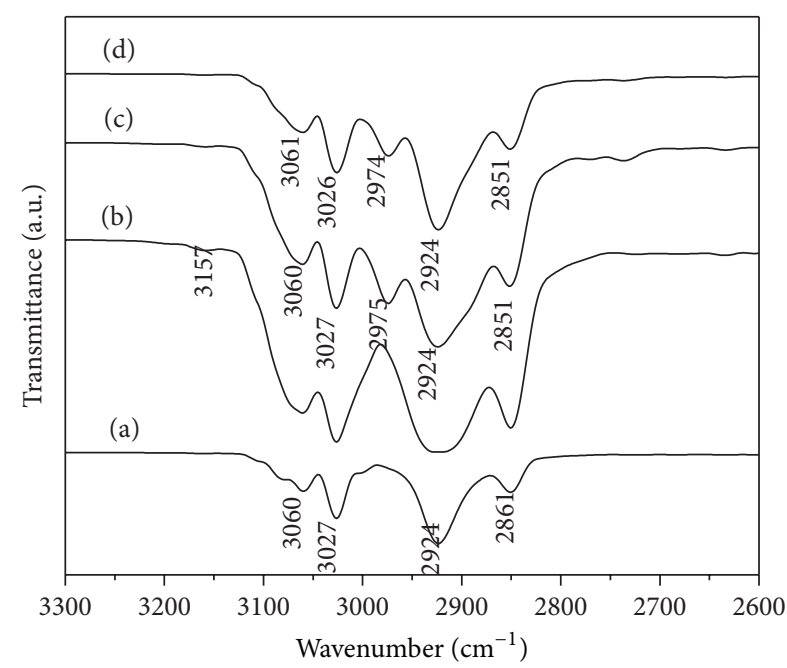

FIGURE 3: FT-IR spectra in the range of $3300-2600 \mathrm{~cm}^{-1}$ of (a) PSR, (b) PSRF, (c) HPSR, and (d) HPSRF materials.

range of 3100 to $3000 \mathrm{~cm}^{-1}$ due to the overlapping of bands proceeding from aromatic groups.

The presence of abietic acid was identified in Figure 2(b) through the signal of carboxyl group $(\mathrm{C}=\mathrm{O})$ in $1691 \mathrm{~cm}^{-1}$, aromatic rings at $1186 \mathrm{~cm}^{-1}$, and $\mathrm{CH}$ bonds at $842 \mathrm{~cm}^{-1}$. The spectrum also shows overlapping bands of PS aliphatic groups and of the initiator in the range of 720 to $800 \mathrm{~cm}^{-1}$ (Figure 2(b)).

Figure 1(c) shows the hybrid polystyrene (HPS) FT-IR spectrum. Vibration of the asymmetric methyl groups $\left(\mathrm{CH}_{3}\right)$ was identified at $2975 \mathrm{~cm}^{-1}$ and symmetric vibration of the $\mathrm{CH}_{3}$ groups appeared in the range of 2960 to $2860 \mathrm{~cm}^{-1}$. Absorption bands at 1107 and $790 \mathrm{~cm}^{-1}$ (Figure 2(c)) correspond to $\mathrm{Si}-\mathrm{O}-\mathrm{Si}$ asymmetric and symmetric vibrations, respectively [21, 22].

The hybrid materials prepared from the recycled polystyrene (HPSR) present the same absorption bands (Figures 3(c) and 4(c)).

The FT-IR spectrum of functionalized hybrid polystyrene (HPSF) shows a broadband at the range of 3200 to $2800 \mathrm{~cm}^{-1}$ (Figure 1(d)) which is associated with the overlapping of the bands due to the aromatic ring present in PS and abietic acid, as well as by the absorption bands of $\mathrm{CH}_{2}$ group at 2925 and $2852 \mathrm{~cm}^{-1}$ [19].

The presence of the Si-O-Si group was identified at 1101 and $964 \mathrm{~cm}^{-1}$ (Figure 2(d)), while the absorption band of the $\mathrm{C}=\mathrm{O}$ group of abietic acid disappears; this same behavior was observed for the functionalized hybrid of recycled polystyrene (HPSRF) in Figures 3(c) and 4(c) [21].

Figures 3 and 4 show the PSR, PSFR, HPSR, and HPSRF spectra in a range of 3300 to $2600 \mathrm{~cm}^{-1}$ and 2000 to $400 \mathrm{~cm}^{-1}$, respectively. Recycled polystyrene (PSR) presents the same characteristic bands of polystyrene (Figures $3(\mathrm{a})$ and $4(\mathrm{a})$ ). In the respective ${ }^{1} \mathrm{H}$-NMR spectrum, a band appears at $5.4 \mathrm{ppm}$, which is associated with other compounds that are present in the recycled material (Figure 6(a)). 


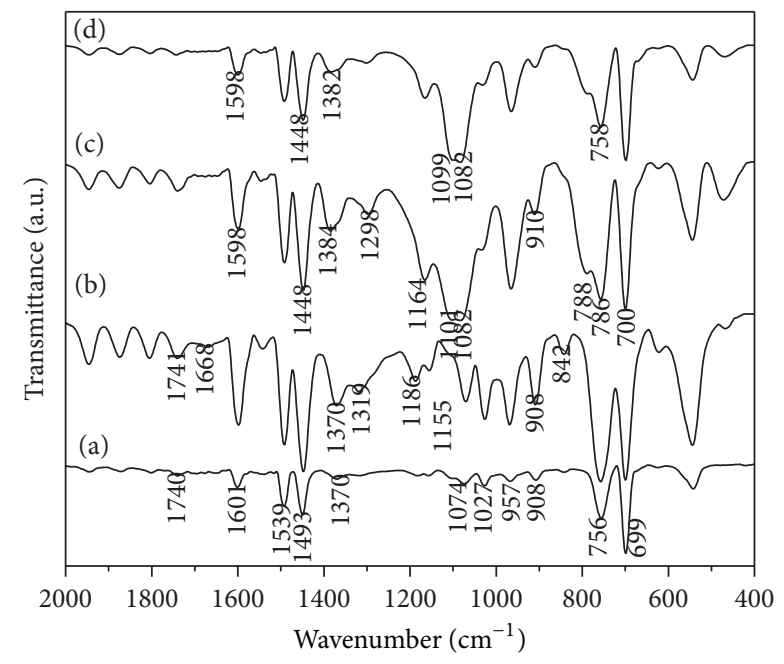

FIGURE 4: FT-IR spectra in the range of $2000-400 \mathrm{~cm}^{-1}$ of (a) PSR, (b) PSRF, (c) HPSR, and (d) HPSRF samples.

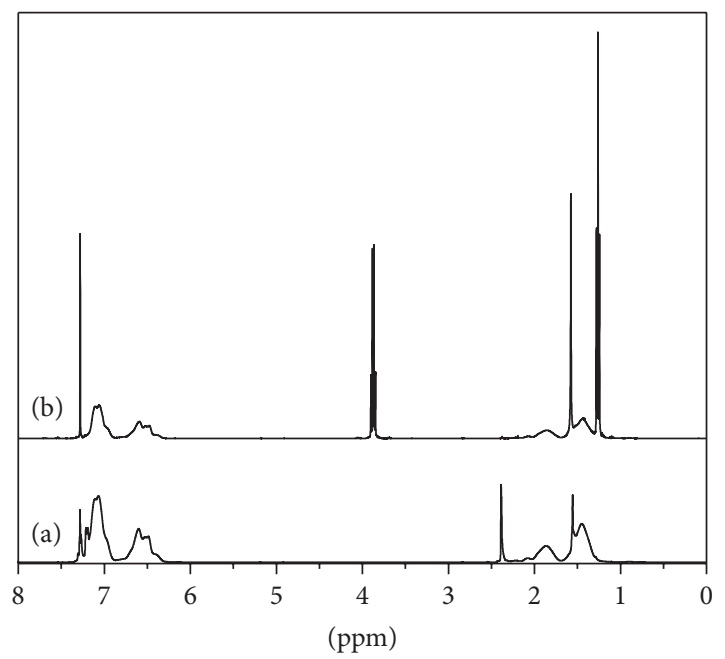

FIgure 5: ${ }^{1} \mathrm{H}-\mathrm{NMR}$ spectra of (a) PS and (b) HPSF materials.

Deformations in the ranges of 2850 to $2980 \mathrm{~cm}^{-1}$ and 2850 to $2980 \mathrm{~cm}^{-1}$ in the FT-IR spectrum of functionalized recycled polystyrene (PSRF) were found (Figure $3(\mathrm{~b})$ ). These deformation bands can be associated with the presence of abietic acid. The signals located at 1688 and $1319 \mathrm{~cm}^{-1}$ correspond to carboxyl group (Figure 4(b)).

Figures 5(b) and 6(b) show the ${ }^{1} \mathrm{H}-\mathrm{NMR}$ spectra of HPSF and HPSRF, respectively. TEOS signals appear at $3.8 \mathrm{ppm}$ and $1.25 \mathrm{ppm}$ for methylene and methyl groups, respectively $\left[\mathrm{CH}_{2}(\mathrm{q})\right.$ and $\left.\mathrm{CH}_{3}(\mathrm{t})\right][20]$.

In both spectra, it is not possible to distinguish abietic acid signals due to the overlap between the aliphatic signals of polystyrenes (PS and PSR). On the other hand, the signals originally located at $2.4 \mathrm{ppm}$ in PS and PSR spectra disappear altogether, thus suggesting an interaction between the functionalized polymers and TEOS.

The TGA and DSC results of these materials show an increase in the amount of silica and functionalization of
TABLE 1: Degradation and glass transition temperatures and contact angle measurements of the studied materials.

\begin{tabular}{lccc}
\hline Material & $\begin{array}{c}\text { Degradation } \\
\text { temperature } \\
\left({ }^{\circ} \mathrm{C}\right)\end{array}$ & $\begin{array}{c}\text { Glass transition } \\
\text { temperature Tg } \\
\left({ }^{\circ} \mathrm{C}\right)\end{array}$ & $\begin{array}{c}\text { Contact angle } \\
\text { on glass }\end{array}$ \\
\hline PS & 299.19 & 54.36 & $85.9623^{\circ}$ \\
PSR & 346.55 & 59.17 & $82.0304^{\circ}$ \\
PSF & 308.04 & 62.07 & $77.4712^{\circ}$ \\
PSRF & 339.24 & 59.72 & $77.4712^{\circ}$ \\
HPS & 221.45 & 56.08 & $81.5966^{\circ}$ \\
HPSR & 318.59 & 57.60 & $87.6863^{\circ}$ \\
HPSF & 338.05 & 76.99 & $88.1720^{\circ}$ \\
HPSRF & 325.26 & 65.24 & $89.2098^{\circ}$ \\
Substrate & & & $37.6262^{\circ}$ \\
\hline
\end{tabular}

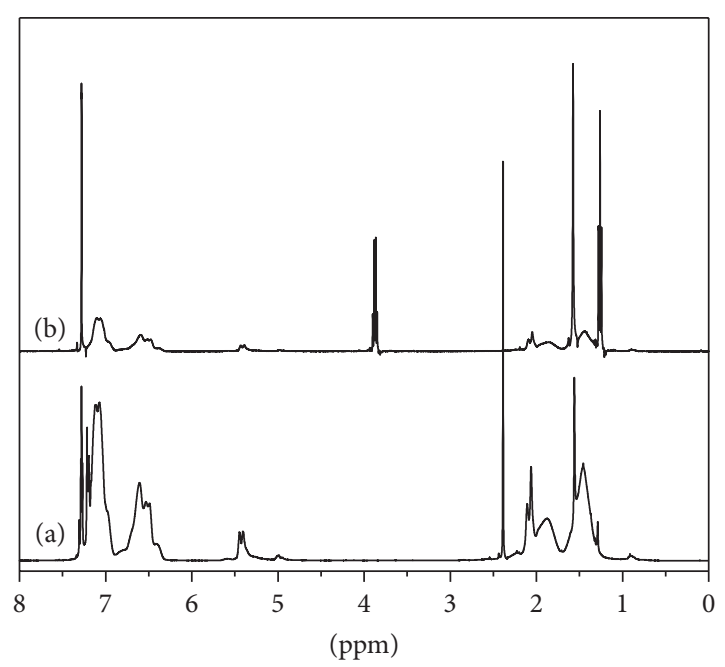

FIgURE 6: ${ }^{1} \mathrm{H}-\mathrm{NMR}$ spectra of (a) PSR and (b) HPSRF materials.

the surface improve the thermal stability of these hybrid materials. The glass transition temperature $(\mathrm{Tg})$ of the hybrid materials increases slightly with the functionalization and amount of silica particles; see Table 1.

The hydrophobicity of the coatings was evaluated by measurement of the contact angle, while establishing the following criteria for having a hydrophilic surface $<40^{\circ}$ and for an acceptable hydrophobic surface $>70^{\circ}$ [14].

The silica nanoparticles incorporated into the polystyrene matrix and combined with the features of the abietic acid allowed obtaining better hydrophobic properties. One manifestation of this hydrophobic surface is the contact angle, which was rather similar in value for the functionalized hybrid materials. All the obtained hybrid materials have a contact angle $>80^{\circ}$. The hybrids of functionalized polystyrene films present an increased contact angle if compared to PS and PSR. This is possible due to the presence of abietic acid, which is an amphiphilic, that is, hydrophobic and hydrophilic, compound and due to the presence of silica particles in the hybrid materials. However, no significant changes in contact angle were observed (Table 1). 


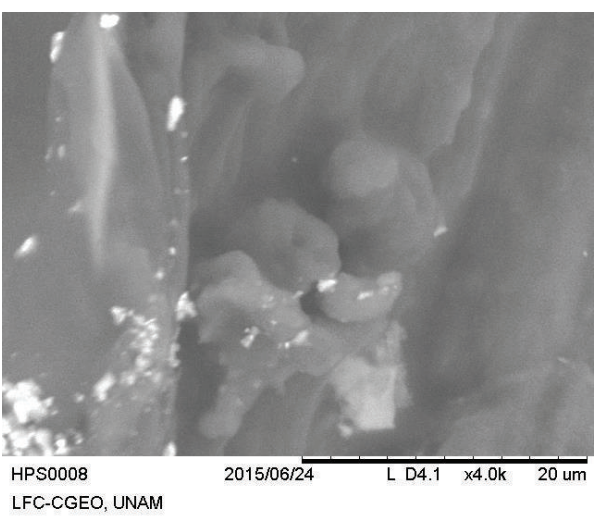

(a)

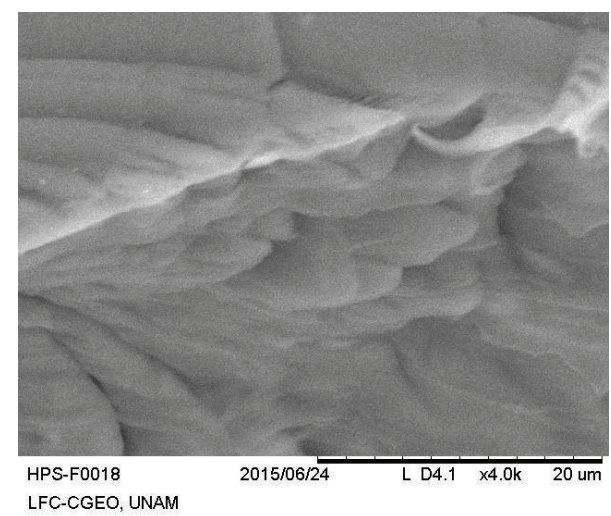

(b)

FIGURE 7: SEM photographs of (a) HPS and (b) HPSF.

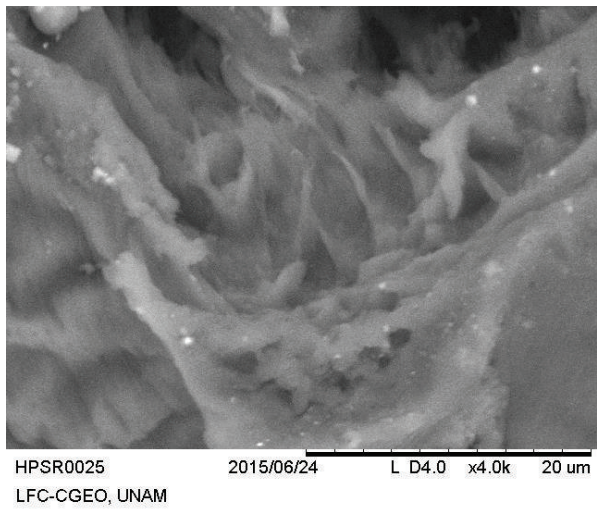

(a)



(b)

FIGURE 8: SEM photographs of (a) HPSR and (b) HPSRF.

In order to know the homogeneity related to the distribution of silica particles on the surface of the hybrid materials, SEM photographs were taken. Figure 7(a) shows aggregates of silica particles on HPS, which indicates that the sample is not homogenous; in the case of HPSF (Figure 7(b)), this sample presents a homogenous surface, thus suggesting an interaction existing between TEOS and functionalized polystyrene.

Hybrid materials micrographs of recycled polystyrene (Figure 8(b)) present a better homogeneity between silica particles and PSR. This suggests that the presence of abietic acid allows silica particles to be dispersed in the polymer matrix, then forming a free surface of aggregates. HPSR depicts smaller aggregates than HPS (Figures 7(a) and 8(a)).

The homogeneous repartition of silica particles is important since it determines the visual transparency or opacity of the final films to finally apply these hybrids as coatings [7].

\section{Conclusions}

Hybrid materials were successfully prepared from recycled polystyrene matrices by introducing silica particles to the polymer matrix by the sol-gel method. Carboxyl groups were identified in the functionalized materials (PSF and PSRF), although this species is absent in the functionalized hybrids (HPSF and HPSRF), thus suggesting that there exists an interaction between carboxyl group and $\mathrm{SiO}_{2} \cdot{ }^{1} \mathrm{H}-\mathrm{NMR}$ analysis shows the presence of other compounds in PSR, which is attributed to recycled material; however, this did not affect the preparation process and neither the hydrophobicity nor the homogeneity properties of functionalized hybrids.

Hybrids of PS and PSR presented segregation of the silica particles on the material surface, while the functionalized hybrids (HPSF and HPSRF) showed a homogeneous surface, thus improving the visual transparency of the coatings. Also, vitreous temperature $(\mathrm{Tg})$ was increased in these materials and the contact angles on the surface of recycled polystyrene were very similar to those found in commercial polystyrene samples.

The properties of recycled polystyrene analyzed in this work are comparable to those ascribed to commercial polystyrene with the possibility that these materials can be used as hydrophobic coatings. Therefore, this study proposes 
a new alternative to the use of recycled polystyrene matrices based on the approach presented.

\section{Conflict of Interests}

The authors declare that there is no conflict of interests regarding the publication of this paper.

\section{Acknowledgments}

The authors thank Dra. Marina Vega for SEM technical support, M. C. Miguel A. Canseco for TGA/DSC technical support, and M. C. Guillermo Vázquez-Sánchez for computational data processing.

\section{References}

[1] T. Maharana, Y. S. Negi, and B. Mohanty, "Review article: recycling of polystyrene," Polymer-Plastics Technology and Engineering, vol. 46, pp. 729-736, 2014.

[2] E. M. Ilgenenfritz, "Plastics waste handling practices in solid waste management," Water, Air, \& Soil Pollution, vol. 4, no. 2, pp. 191-198, 1975.

[3] H. Zou, S. Wu, and J. Shen, "Polymer/silica nanocomposites: preparation, characterization, properties, and applications," Chemical Reviews, vol. 108, no. 9, pp. 3893-3957, 2008.

[4] C. Sanchez, P. Belleville, M. Popall, and L. Nicole, "Applications of advanced hybrid organic-inorganic nanomaterials: from laboratory to market," Chemical Society Reviews, vol. 40, no. 2, pp. 696-753, 2011.

[5] V. A. Gerasin, E. M. Antipov, V. V. Karbushev et al., "New approaches to the development of hybrid nanocomposites: from structural materials to high-tech applications," Russian Chemical Reviews, vol. 82, no. 4, pp. 303-332, 2013.

[6] H. S. Vaziri, M. Abadyan, M. Nouri, I. A. Omaraei, Z. Sadredini, and M. Ebrahimnia, "Investigation of the fracture mechanism and mechanical properties of polystyrene/silica nanocomposite in various silica contents," Journal of Materials Science, vol. 46, no. 17, pp. 5628-5638, 2011.

[7] G. Hernández-Padrón, F. Rojas, M. García-Garduño, M. A. Canseco, and V. M. Castaño, "Development of hybrid materials consisting of $\mathrm{SiO}_{2}$ microparticles embedded in phenolicformaldehydic resin polymer matrices," Materials Science and Engineering A, vol. 355, pp. 338-347, 2003.

[8] W. Stevenson and J. R. White, "Photo-sensitivity of recycled photo-degraded polystyrene," Journal of Materials Science, vol. 37, pp. 1091-1100, 2012.

[9] C. Borsoia, K. H. Berwigb, L. C. Scienzac, B. C. D. A. Zoppasd, R. N. Brandalisea, and A. J. Zatteraa, "Behavior in simulated soil of recycled expanded polystyrene/waste cotton composites," Materials Research, vol. 17, no. 1, pp. 275-283, 2014.

[10] D. R. Hwang, J. Hong, J. Lee, and S. E. Shim, "In-situ synthesis of PS/(-)silica composite particles in dispersion polymerization using an ( \pm ) amphoteric initiator," Macromolecular Research, vol. 16, no. 4, pp. 329-336, 2008.

[11] G. Hernández-Padrón, M. Garcia-Garduño, and F. Rojas-González, "Hybrid materials based on functionalised epoxy resin networks," Pigment \& Resin Technology, vol. 39, no. 4, pp. 195-202, 2010.
[12] T. Kotoky and S. K. Dolui, "Synthesis of polystyrene/silica hybrid composites by the sol-gel method: effect of introduction of a flexible component (butyl acrylate) into the silylated polystyrene backbone," Colloid and Polymer Science, vol. 284, no. 10, pp. 1163-1169, 2006.

[13] B. Ou and D. Li, "Preparation of polystyrene/silica nanocomposites by radical copolymerization of styrene with silica macromonomer," Science in China Series B: Chemistry, vol. 50, no. 3, pp. 385-391, 2007.

[14] J. A. Howarter and J. P. Youngblood, "Self-cleaning and next generation anti-fog surfaces and coatings," Macromolecular Rapid Communications, vol. 29, no. 6, pp. 455-466, 2008.

[15] U. C. Nwaogu and N. S. Tiedje, "Foundry coating technology: a review," Materials Sciences and Applications, vol. 2, no. 8, pp. 1143-1160, 2011.

[16] M. C. Wilkinson, J. Hearn, and P. A. Steward, "The cleaning of polymer colloids," Advances in Colloid and Interface Science, vol. 81, no. 2, pp. 77-165, 1999.

[17] G. Hernández-Padrón, F. Rojas, and V. M. Castaño, "Ordered $\mathrm{SiO}_{2}$-phenolic formaldehyde resin in situ nanocomposite," Nanotechnology, vol. 15, no. 1, pp. 98-103, 2004.

[18] G. Hernández-Padrón, T. Gómez-Quintero, and A. BlancoHernández, "Development antifog nanohybrid consisting of polystyrene recycled matrix by sol-gel process," in Proceedings of the Nanotechnology: Technical Proceedings of the NSTI Nanotechnology Conference and Expo, vol. 1, pp. 218-219, Washington, DC, USA, May 2014.

[19] B. C. Smith, Infrared Spectral Interpretation A Systematic Approach, CRC Press, 1998.

[20] R. M. Silverstein, C. G. Basstler, and T. C. Morrill, Spectrometric Identification of Organic Compounds, chapter 4, John Wiley \& Sons, New York, NY, USA, 3rd edition, 1974.

[21] N. B. Colthup, L. H. Daly, and S. E. Wiberley, Introduction to Infrared and Raman Spectroscopy, Academic Press, San Diego, Calif, USA, 3rd edition, 1990.

[22] G. Orcel, J. Phalippou, and L. Hench, "Structural changes of silica xerogels during low temperature dehydration," Journal of Non-Crystalline Solids, vol. 88, no. 1, pp. 114-130, 1986. 



Submit your manuscripts at http://www.hindawi.com


\section{The Scientific World Journal}
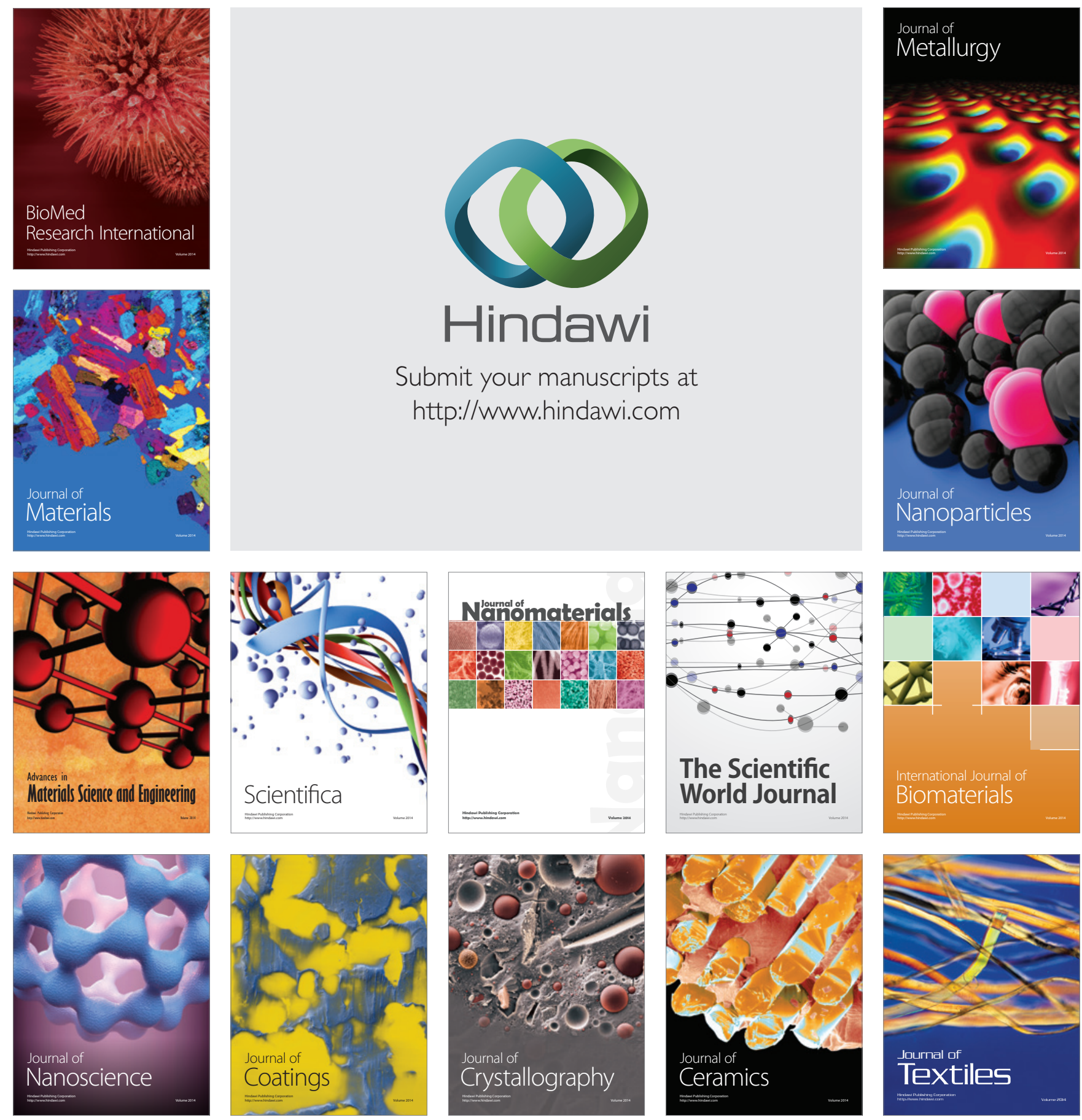